
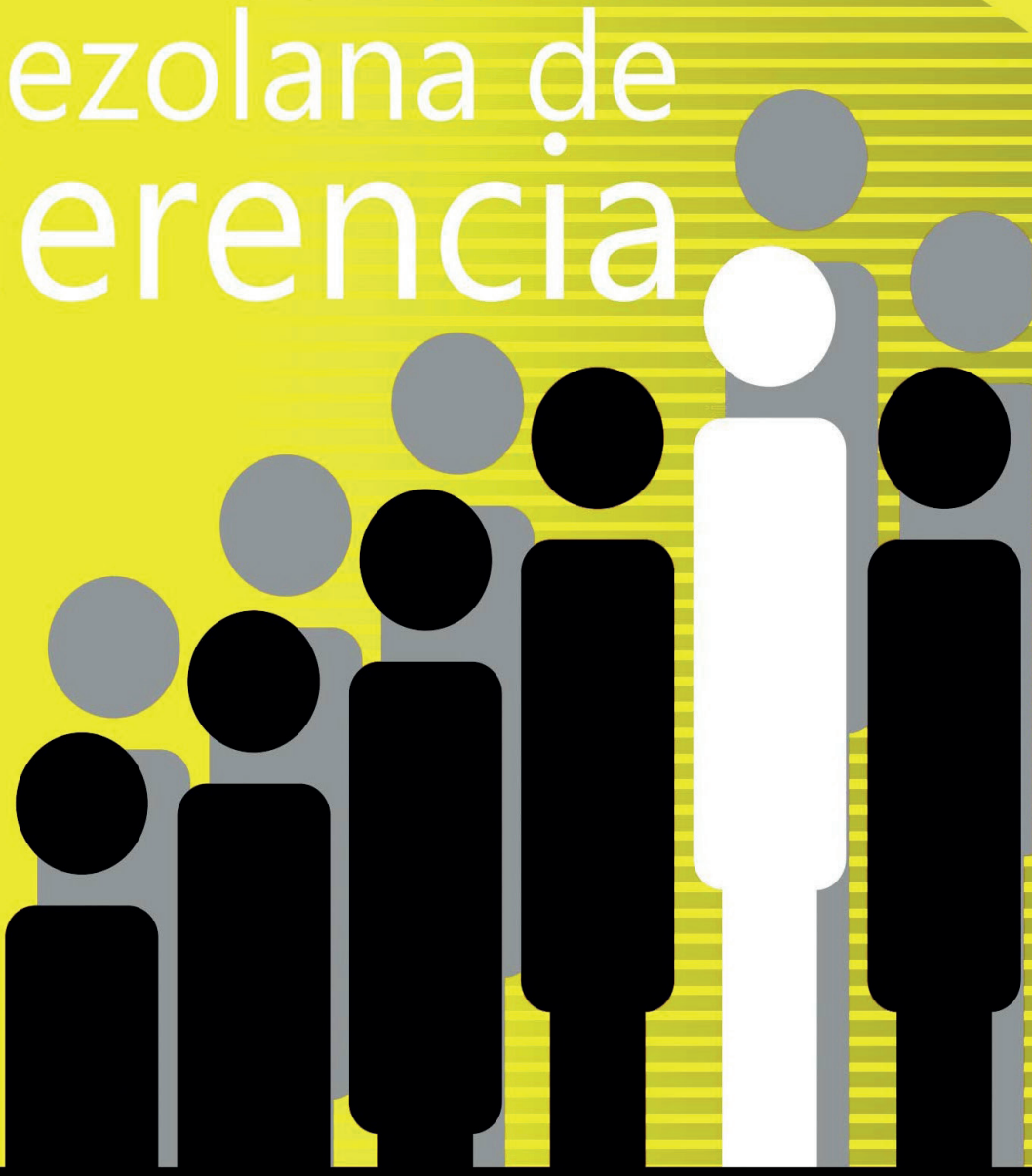


\title{
Ética en las organizaciones sindicales venezolanas: una mirada desde lo teórico-legal
}

\author{
Noroño Sánchez, José Gregorio* \\ Baquero Suarez, Tania Marina* \\ Vílchez Pirela, Rafael ${ }^{* * *}$ \\ Soto, Olga Lucía ${ }^{* \star \star}$
}

\section{Resumen}

El presente artículo de investigación analiza la ética desde los aspectos teóricos y legales en las organizaciones sindicales de Venezuela. Para ello, se consultaron los criterios de prestigiosos doctrinarios y la LOTTT (2012). Se hizo un recorrido por las principales dimensiones éticas donde hacen vida esta clase de organismos especialmente las fundadas en empresas privadas. La metodología aplicada en el presente estudio se sustenta dentro del método cualitativo, se hace igualmente uso del análisis crítico, aplicando la hermenéutica como base de las interpretaciones. Entretanto, se demuestra que existen suficientes elementos, tanto teóricos como legales, para fomentar la conducta ejemplar por parte de estas organizaciones de representación colectiva. Las principales conclusiones están enfocadas en la construcción y transformación del comportamiento ético que deben desplegar las organizaciones sindicales a los fines de cumplir con sus propósitos legales en beneficio de sus agremiados, así mismo, se hace

\section{Recibido: 07.10.20 Aceptado: 15.02.21}

* Postdoctor en Integración y Desarrollo de América Latina, Doctor en Ciencias Gerenciales, Magister Scientiarum en Derecho del Trabajo y Abogado, Docente e Investigador de la Universidad del Sinú Elías Bechara Zainúm (Montería - Colombia), ORCID: https://orcid.org/0000-0001-9777-2733

** Doctora en Ciencias Políticas. Magister en Derecho. Especialista en Derecho Administrativo. Especialista en Sistemas de Calidad y Auditoría de Servicios de Salud. Especialista en Gerencia Tributaria. Abogada. Docente Investigadora de la Corporación Universitaria Americana (Atlántico, Barranquilla). E-mail: tamabasu@gmail. com ORCID: https://orcid.org/0000-0002-1881-7567

*** Postdoctor en Gerencia de las Organizaciones. Doctor en Ciencias Gerenciales. M.Sc. en Gerencia de Recursos Humanos. Licenciado en Trabajo Social. Docente e Investigador de la Corporación Universitaria del Caribe - CECAR - Sucre- Colombia. ORCID: https://orcid.org/0000-0003-4473-7584

**** Msc. Trastornos Cognoscitivos y del Aprendizaje. Psicólogo de la Universidad del Norte. Docente e Investigador de la Corporación Universitaria del Caribe - CECAR - Sucre- Colombia ORCID: https://orcid. org/0000-0001-6974-9026 
un esbozo del aspecto teórico de la legislación aplicable con el propósito de evidenciar sus interacciones naturales y como subyacen en sus diferentes contextos éticos.

Palabras Clave: Ética; Empresas Privadas; Sindicatos; Dimensiones de actuación Sindical; Dirigentes.

\title{
Ethics in Venezuelan trade union organizations: a theoretical-legal perspective
}

\begin{abstract}
This research article analyses ethics from the theoretical and legal aspects of trade union organizations in Venezuela. To this end, the criteria of prestigious doctrines and the Labour Law (2012) were consulted. It took a tour of the main ethical dimensions where these kinds of organisms come to life, especially those founded on private companies. The methodology applied in this study is based on the qualitative method, the critical analysis is also used, applying hermeneutics as the basis of interpretations. Meanwhile, it is shown that there are sufficient elements, both theoretical and legal, to encourage the exemplary conduct by these collective representation organizations. The main conclusions are focused on the construction and transformation of ethical behavior or that union organization must be deployed to fulfill their legal purposes for the benefit of their aggressed, as well as an outline of the theoretical aspect of the applicable legislation to highlight their natural interactions and how they underlie in their different ethical contexts.
\end{abstract}

Keywords: Ethics; Private Companies; Trade Unions; Trade Union Action Dimensions; Leaders.

\section{Introducción}

Según la autora española y ganadora del Premio Internacional de ensayos Jovellanos, Cortina (2013) la ética representa una reflexión hecha a la vida, pero usando la filosofía, en este sentido, representaría la acción humana vista desde la percepción del aspecto teórico de la misma, la cual, está estrechamente ligada al carácter con el que forjamos nuestra conducta y decidimos vivir. Dicho de otra forma, la ética es la filosofía derivada de la conducta que asumimos en la vida.

En consideración a lo anterior, la presente investigación se circunscribe en la construcción y establecimiento del comportamiento que deben evidenciar las organizaciones sindicales de trabajadores del sector privado en Venezuela, esto a los fines de establecer lineamientos teóricos, legales y éticos que beneficien tanto a los dirigentes, como a los miembros en dichas organizaciones de representación 

Ética en las organizaciones sindicales venezolanas: una mirada desde lo teórico-legal_

colectiva. Tal modelaje, permitirá establecer las estrategias metodológicas y de análisis crítico, así como brindar guía en cada uno de los escenarios naturales y teórico-legales donde interactúan los sindicatos en concordancia con Añez (2014).

Deconformidad con la Organización Internacional del Trabajo (1995:14, en lo sucesivo, OIT) ${ }^{1}$ las principales circunstancias a que se enfrentan las organizaciones sindicales estriban en la falta de capacitación, educación y formación de los dirigentes, siendo que, llegan a ostentar tales responsabilidades dentro del organismo sin el mínimo conocimiento legal, lo cual permite a sus contrapartes, tener un paso adelante a la hora de existir diferencias, o reclamar conceptos laborales, mientras que también se desconoce el componente ético de los integrantes.

La problemática anterior, requiere ser analizada y estudiada, en primer lugar, para determinar el entramado de problemas sociales y económicos que se derivan de su diario vivir, así mismo, en segundo lugar, para identificar los posibles dilemas o debilidades éticas a los fines de proponer lineamientos teóricos con base legal, que redireccionen e impulsen un nuevo modelo de comportamiento, con los propósitos claros de superación social y económica.
Es por lo que, se realizará el análisis partiendo de sus relaciones intersubjetivas, dentro de las que se encuentran, las derivadas de la dimensión intrasindical, empresarial, de representación ante el patrono y sus diferentes interacciones con los organismos públicos.

\section{La Ética y los aspectos teóricos}

En Venezuela desde 1999, año en que asumió la presidencia por primera vez la denominada izquierda política, se originaron una serie de cambios $y$ actividades que promovieron el nacimiento de una nueva clase sindical, respaldada por el ejecutivo nacional, con la intención de empezar una nueva escena laboral en el país y hacerle frente al sindicalismo histórico presente en la nación, contra la Confederación de Trabajadores de Venezuela - (CTV $)^{2}$, tal comportamiento no vino apalancado por estructura sindical de base, sino, paralela a las ya establecidas. La intención fue desde siempre clara, eliminar la antigua estructura sindical y experimentar con una nueva visión política, el denominado Sindicalismo Bolivariano ${ }^{3}$.

Es sin duda, una gran tarea indagar en criterio de Noroño (2019:65) y Dickens y Goodwing (1981:109) sobre el comportamiento ético de las

1 OIT: Fue fundada en 1919, como parte del Tratado de Versalles que dio por terminada la Primera Guerra Mundial, y desde sus bases y convicciones se enmarca con la justicia social como eje esencial para alcanzar la paz universal, duradera y permanente. https://www.ilo.org/global/about-the-ilo/history/lang--es/index.htm

2 Fundada en 1936, fue la central más robusta que existió en Venezuela hasta que el presidente Hugo Chávez, cansado de su oposición se propuso su eliminación del escenario laboral venezolano, utilizando todos los mecanismos disponibles, legales, o no, para intentarlo, aunque le imprimió fuertes daños, todavía dicha central se mantiene limitadamente activa, pero con breves reductos de vida.

3 La palabra Bolivariano (a), identifica a todo adepto al movimiento político encabezado por el expresidente Hugo Chávez (1954-2013). 
organizaciones tradicionales, las cuales, fueron tildadas de poco honestas y de haber quemado el progreso sindical según Urquijo (2004), por cuanto, y a criterio de los investigadores, las actuales organizaciones sindicales del país, no se comparan en ninguna forma a las peores circunstancias sindicales observadas en la historia republicana de Venezuela antes de 1999, en razón a que, el sindicalismo de esa época dejó un dechado de logros y beneficios a pesar del ataque recibido a partir de la llegada del Socialismo del Siglo $\mathrm{XXI}$, por tanto, se aspira que la nueva generación "Bolivariana", resultante de esta nueva historia, tenga la capacidad de posicionarse de forma digna ante los trabajadores, empresarios, empleadores y ante los organismos públicos.

Tomando en consideración lo expresado, por Noroño et al, (2020a:156) resulta importante, establecer los mecanismos disponibles que tienen las organizaciones sindicales para lograr el éxito, en atención a la simbiosis que debe existir entre las leyes laborales, contables, económicas, financieras y tributarias de conformidad con Baquero y Liñán (2020), por tanto, fomentan el comportamiento ético, según lo expresado por Flórez, López y Vílchez (2020) en razón de que impulsa la sinergia en tales ambientes, aun teniendo intereses contrapuestos.

Laética sindical, en el criterio de los investigadores es la conducta ejemplar, basada en principios moralmente aceptables, rectitud demostrada con equidad y justicia, que se manifiesta en el actuar y comportamiento del dirigente sindical en sus diversas formas, esferas, dimensiones y modalidades, donde poseen actividad e intereses sus organizaciones, miembros y asociados, con las cuales se impulsa, apalancan y persiguen el componente ético para el logro y consecución de los objetivos comunes.

Cabe acotar, que de acuerdo con Offe (1983:71) las organizaciones sindicales poseen una un plano diverso de escenarios, donde se pone a prueba la conducta, es por ello, necesario dejar de lado los ambages, y reconocer que existen elementos éticos que hay que crear y fortalecer con el fin de lograr que el liderazgo sindical, brinde desarrollo progresivo a los beneficios socioeconómicos de sus representados y se deslastre de viejas prácticas perniciosas, hoy comunes en criterio de los investigadores.

A este respecto, el comportamiento ético, de conformidad con Noroño y Núñez (2020b) puede dividirse en varias esferas o dimensiones propias de la vida sindical, entre las que se pueden contar, dentro de la entidad de trabajo o empresa, ante los trabajadores y ante los organismos públicos con los cuales hacen interacción permanente, por solo mencionar tres de las más sensibles, pudiendo estas generar al mismo tiempo otras subdivisiones o subcategorías.

Al mismo tenor, en concordancia con Gamboa et al, (2003:25) y Schmitter (1983:288) intentar construir un modelo ético, implica más que simples postulados conductuales, o decálogos de actuación para el sindicato; engloba posibilidades, aportes basados en la observación y la transformación del organismo sindical en base al estudio del componente teórico y jurídico existente.

Aunque no se pretende emplazar, ni de alguna forma forzar el comportamiento ético-sindical, se desarrollan acercamientos teóricos sobre la conducta asumida por el organismo sindical, los afiliados al sindicato y la conducta que despliegan en el nexo 

Ética en las organizaciones sindicales venezolanas: una mirada desde lo teórico-legal_

con la entidad de trabajo, con el fin de ejemplificar el actuar, transitar o caminar del organismo sindical y de quienes los respaldan, sin que esto indique que sus variaciones 0 alteraciones impliquen una conducta que se aleje de lo ético, lo moral y lo correcto según Schmidt (1982:126).

Dadas las consideraciones anteriores, con tales aportes, se persigue fortalecer y reforzar la conducta éticasindical para que ésta, agregue valor tanto a las relaciones laborales como a los actores del mundo sindical, como lo son el entorno laboral de la empresa, sus afiliados, y el entorno de interacción con organismos públicos, de conformidad con Noroño y Seijo (2016:176).

\section{Dimensión Ética Sindical y la Empresa}

Los autores Thompson y Strickland (1999:98), reconocen que es en la empresa, donde las organizaciones de tipo privado se encuentran inmersas, en este sentido, el dirigente sindical no debe olvidar que los pactos proyectados deben crear beneficios, superar los establecidos y mejorar la calidad de vida de sus representados, es por ello, que su meta principal, debe centrarse en complacer a sus agremiados, respaldar las mejoras en la productividad sin menoscabo de beneficios y brindar oportunidades para todos y no únicamente a aquellos trabajadores que comulgan con la visión sindical.
En este sentido, el sindicato, debe interactuar con el empleador, sin embargo, no debe asumir el discurso productivo como eje central de su cotidianidad, por cuanto, lograría confundir a sus trabajadores sobre las metas del organismo colectivo, tal como lo explica Añez y Bonomie (2007) en este sentido, se aspira que el sindicato se interese por mantener una empresa productiva, sustentable y sostenible, sin menoscabo de la progresividad $y$ continuidad de los beneficios derivados de la relación de trabajo.

En el campo de las atribuciones, son muchas las aristas que deben tener en consideración quienes asumen la responsabilidad de representar a la clase trabajadora, por eso, no se debe olvidar que el sindicato debe perseguir la continua mejora de sus agremiados, en este sentido, debe buscar el progreso económico y social de sus representados, para ello, está facultado para presentar, discutir y negociar las convenciones colectivas de trabajo ante las autoridades competentes.

A tenor de lo expuesto, es moralmente ético por parte de las organizaciones sindicales y sus integrantes, presentarse ante la autoridad electoral para solicitar en el tiempo que indiquen los propios estatutos sociales, el proyecto de elecciones sindicales, mediante el cual, se legitima la Junta Directiva, no solo ante sus agremiados, sino también ante el patrono, ya que de conformidad con el artículo 402

\footnotetext{
4 LOTTT (2012) Ley Orgánica del Trabajo, los Trabajadores y las Trabajadoras publicada en la (Gaceta Oficial N 6.076 Extraordinario del 7 de mayo de 2012). https://oig.cepal.org/sites/default/files/2012 leyorgtrabajo ven. pdf
} 
de la Ley Orgánica del Trabajo, los Trabajadores y las Trabajadoras (en lo sucesivo LOTTT 2012) ${ }^{4}$, sino se adecúa a lo preceptuado, no podrá celebrar actuaciones que excedan de la simple administración, entendiendo por eso, que tampoco podrá de conformidad con las atribuciones ya descritas, defender eficazmente a los trabajadores ni presentar reclamaciones colectivas ante los organismos competentes.

Por consiguiente, prestar atención a los lapsos establecidos tanto en los estatutos de la organización como en la ley para celebrar elecciones sindicales y presentar toda clase de reclamos y peticiones a tiempo, redunda no solo en beneficios particulares para los líderes que conforman la Junta Directiva, sino que también, ese beneficio es directamente proporcional a los afiliados, puesto que, se discutirán las mejoras proyectadas en el tiempo preciso, por el contrario, al no observar los lapsos legales descritos, esa conducta irresponsable sumerge a los afiliados en un retraso económico por cuanto la demora en la discusión y negociación de la convención colectiva, pudiendo someter a daños patrimoniales al trabajador por la tranquilidad e inobservancia de los líderes sindicales.

Tales disposiciones, surgieron en criterio de Urquijo (2004) ya que las organizaciones sindicales venezolanas tenían juntas directivas indefinidas $y$ perpetuas, muchas veces no celebraban elecciones sindicales, sino que fundaban una nueva organización sindical para no declarar fondos y esto perturbó la escena laboral con mandatos indefinidos y opacidad en el uso de los recursos provenientes de los aportes de cada afiliado a la organización, situación que a criterio de los investigadores, se corrigió con esta norma intentando obligar la transparencia en el manejo de los fondos sindicales y la publicación de los mismos ante una asamblea de trabajadores.

Ante tales eventos, las responsabilidades son variadas, con referencia a los fondos sindicales también hay normas legales que establecen procedimientos obligatorios para el correcto funcionamiento de las organizaciones sindicales, entre las que se encuentran las establecidas en los artículos 415 y 417 de la LOTTT (2012), donde se obliga al organismo a declarar anualmente y mediante una asamblea general de miembros, el destino y uso de los recursos aportados por los miembros, impulsando así, la propia Ley, al escrutinio público de las finanzas sindicales y transparencia, por lo menos, en lo que respecta a disposición legal.

Demostrado como ha sido, las estipulaciones legales existentes en el ordenamiento jurídico venezolano, se procede a establecer de forma general, los aportes sobre el componente ético que debe existir en los organismos sindicales con respecto a la dimensión interna y concerniente al trato con los afiliados, para ello, se toma como anclaje los principios rectores estipulados del derecho del Trabajo enarbolados en el artículo 18 y siguientes de la LOTTT (2012).

En este sentido, un organismo sindical, según se desprende de la lectura de esta norma de carácter orgánica, jamás podrá tolerar actos injustos del patrono en contra de sus afiliados y agremiados, lo que incluyen, situaciones donde se puedan pactar la pérdida, desmejora o menoscabo de beneficios individuales o colectivos, por prerrogativas o beneficios particulares, al contrario, debe propender al desarrollo progresivo de los beneficios pactados. Por otro lado, debe velar por el correcto uso de la ley, y ante la celebración de 

Ética en las organizaciones sindicales venezolanas: una mirada desde lo teórico-legal_

contratos de trabajo, debe verificar por la correcta interpretación de normas de rango legal que no afecten los derechos y garantías establecidas para la protección del trabajador.

De esta manera, indican Noroño, Chacín y Núñez (2019:44) se evitará la errónea interpretación de normas que afecten el sano ejercicio del derecho al trabajo, por su parte el organismo sindical, tiene la comisión de velar por la correcta ejecución de las normas de protección, higiene y seguridad en el lugar de trabajo, por consiguiente, se recomienda ser celosos a la hora de exigir tanto la dotación como el uso de los equipos de protección personal, de modo que se garantice la salud ocupacional de los trabajadores.

En síntesis, el ámbito de las atribuciones y responsabilidades otorgadas a los sindicatos también les faculta para perseguir, denunciar y combatir todas aquellas prácticas patronales o gerenciales que tengan por objeto la discriminación de cualquier índole o que tengan por objeto la segregación, fraccionamiento, atomización o división del movimiento sindical y las conductas poco éticas contra la propia organización sindical.

Por consiguiente, los principios laborales donde se fundamenta la LOTTT (2012), brindan un fuerte contenido de dirección ética al sindicato, entre tanto su observación y análisis aporta en principio, la guía necesaria para el buen actuar, tales directrices representan la irrenunciabilidad de los derechos laborales, la obstrucción a la relajación de normas y la imposibilidad de celebrar o eliminar con el uso de transacciones, beneficios obtenidos mediante convenciones colectivas donde se viole de forma alguna los principios constitucionales referidos a la protección de derechos laborales.

En virtud de lo expuesto, es importante que las organizaciones sindicales tengan conciencia y perfecto conocimiento de las implicaciones relativas a la celebración de transacciones laborales que a criterio de Rangel y Alvarado (2012:43) versen sobre puntos de derecho de los trabajadores, en el entendido de que cualquier convenio se considerará nulo, si perjudica, agrede o desmejora al trabajador, además es moralmente correcto y éticamente aceptable que los líderes sindicales tengan claros los conceptos en los que se fundamentan la irrenunciabilidad de los derechos y garantías laborales.

Por otro lado, en el artículo 20 de la LOTTT (2012), se establece el principio de igualdad y equidad de género, siendo que esta disposición obliga a la participación paritaria de hombres y mujeres en el proceso social de trabajo. Es en este caso, donde se parte del análisis de las atribuciones y finalidades de las organizaciones sindicales, donde se observan sus responsabilidades. Para ello, se parte del artículo 2 constitucional y los artículos 354,355 y 356 de la LOTTT (2012), donde se esboza, que Venezuela se constituye en un Estado democrático y Social de Derecho y Justicia, enmarcado en valores como la libertad, la responsabilidad y el pluralismo político, entre otros.

Por su parte, la LOTTT (2012), haciendo eco de las libertades constitucionales les otorga plena autonomía, libertad y protección a las organizaciones sindicales en su artículo 354 , desarrollando en el artículo 355 y 356 lo que implica los derechos individuales y colectivos para el trabajador venezolano. 


\section{Dimensión Ética desde lo Legal}

No obstante, estos artículos no son los únicos en los cuales se determina el ámbito de actividad de las organizaciones sindicales, ya que los que anteceden explican la dimensión individual y colectiva, sin tomar en consideración las internas, para ello, también es imprescindible analizar los artículos 365 , 367 y 368 del LOTTT (2012), entre otros, donde, el legislador patrio, concibe algunas de las actividades a las que por ley tienen derecho los sindicatos, sin embargo, estas son enunciativas y jamás taxativas, ya que no limitan bajo ningún modo el actuar sindical, sino más bien, porque dejan abierta la posibilidad que los individuos que las integran decidan el mejor camino para las mismas, sin más limitaciones que las establecidas en el ordenamiento jurídico.

Por otra parte, la LOTTT (2012), le confirió ciertas responsabilidades a las organizaciones sindicales, las cuales están recogidas en el artículo 388. Por consiguiente, no es para sorprenderse que autores como Villasmil (2006:117) indica que el Estado Venezolano usa el método o "modelo dirigísta", cuando se refiere a las organizaciones sindicales, situación que antagoniza con los postulados abiertos institucionalizados por la OIT, en donde tales actividades pudieran ser observadas como injerencistas, debido a que no se les otorga la participación a las organizaciones, sino que es un mandato legal.

Comenzando por el análisis de las disposiciones legales contendidas en la LOTTT (2012), dicha norma posee varias limitaciones legales para las organizaciones sindicales entre las que se enumeran las estipulaciones resumidas en los artículos 401 y 402 de la LOTTT (2012), donde se explica que, todo organismo sindical tiene la posibilidad de ejercer sus funciones por un período de tres (3) años, para organizaciones de primer grado y hasta cinco (5) para organismo de segundo y tercer grado, debiendo efectuar sus procesos electorales por ante y bajo el acompañamiento del Consejo Nacional Electoral (en lo sucesivo, CNE) del país, y estableciendo la limitación de que, todas aquellas organizaciones sindicales que vencido el lapso máximo de tres años, y no hayan celebrado su proceso de elección a lo interno del sindicato con la guía, vigilancia y supervisión del CNE, no podrán celebrar actos sino, únicamente de representación hasta tanto quede demostrado el cumplimiento de dicha norma.

Adicionalmente, los horarios protegidos y flexibles para la lactancia infantil de los hijos de las trabajadoras, resulta, en molestias para algunos, por ende, el líder sindical, no debe permitir que tales disposiciones de índole legal se vean afectadas dentro de sus entidades de trabajo, por el contrario, es ético velar por el cumplimiento tanto de estas normas de carácter humanista, así como también sobre el establecimiento del mejor horario para las madres trabajadoras.

Tales son, en síntesis, los principios laborales que rigen en Venezuela en materia de protección al trabajo como hecho social, por consiguiente, el artículo 21 de la LOTTT (2012), describe una garantía crucial, tal como lo es, la prohibición de prácticas discriminatorias, que puedan incluir una distinción, posible exclusión, preferencia o restricciones en la garantía y en las condiciones de trabajo, fundamentadas en motivos de raza, sexo, edad, estado 

Ética en las organizaciones sindicales venezolanas: una mirada desde lo teórico-legal_

civil, sindicalización, religión, opiniones políticas, nacionalidad, orientación o preferencia sexual, personas con disminución de capacidad u origen, o estrato social, que limiten o socaven el derecho al trabajo, sin embargo, tal garantía no se cumple en el escenario laboral hoy.

Es por ello entonces, que se señala como ilegal, desplegar cualquier clase de discriminación, contravención ética, y violación flagrante a las disipaciones establecidas dentro del referido artículo 21, y principio fundamental del derecho laboral venezolano, por otra parte, se observa, que el andamiaje jurídico que protege la escena laboral está construido sobre principios importantes, que, al analizarlos en detalle, otorgan un referente ético oportuno para cualquier líder sindical, entre otros.

Así entonces, se describe el cúmulo de garantías que persiguen modelar la conducta que debe privar en las relaciones laborales de hoy, es así, como llegamos al artículo 22 de la LOTTT (2012), donde se enuncia el principio de primacía de la realidad sobre las formas, tipos o apariencias para la interpretación y aplicación en materia especial y social referida a los derechos y garantías laborales, donde, se declaran nulas y de pleno derecho todas aquellas medidas, comportamientos, actos, actuaciones, intenciones, fórmulas y convenios adoptados por el patrono en franco fraude la esta Ley, así también como todas aquellas destinadas a simular las relaciones de trabajo y al mismo tiempo intentando precarizar sus condiciones.

En el análisis de dicho principio, se obtiene de su interpretación jurídica, que cualquier fórmula, método, mecanismo, forma o apariencia que, de alguna manera, se pretenda usar para desvirtuar las relaciones laborales, será nula y sus efectos considerados írritos y sin validez, por cuanto, el principio, establece que el intento de fraude, evasión o inobservancia, solo generan la penalización legal con las consecuencias jurídicas que favorecen al trabajador.

Es entendido que, en las relaciones laborales, los organismos sindicales deben proteger a sus agremiados de los intentos por tercerizar, externalizar y satelizar procesos de trabajos fuera del amparo de la ley, en desmedro de los trabajadores. Por tal motivo, no es ético, aceptar, aprobar, pactar o consentir condiciones de trabajo que no estén ampliamente autorizadas ni aprobadas por los órganos competentes en materia de Derecho del trabajo y la seguridad social, es por lo que, se entiende, que tales formas ajenas a la ley solo reportan modernas formas de explotación y que al mismo tiempo significan un ahorro significativo para los propietarios de los medios de producción y la mano de obra.

Ante tales circunstancias, por demás peligrosas para los beneficios de los trabajadores, se observa necesario empoderar al organismo sindical para que construya una estructura ética que le permita reconocer con facilidad las estrategias empresariales que persiguen la precariedad y el empobrecimiento sistemático del trabajador, para ello se dispuso del artículo 23 de la LOTTT (2012).

Dicho artículo precedente, establece la orientación a los medios alternos de resolución de conflictos para resolver desavenencias y conflictos entre trabajadores y empleadores, y se ordena un proceso expedito, uniforme, breve, que imponga lo gratuito, la celeridad, oralidad, inmediatez, concentración, prioridad de la realidad de los hechos, la equidad, la mediación y rectoría del juez dentro del proceso, la sencillez, la 
eficacia, la accesibilidad, la imparcialidad, la idoneidad, la transparencia, la autonomía, la independencia, la responsabilidad, con el fin de darle atención al debido proceso, evitando las dilaciones indebidas, y eliminando los formalismos o reposiciones que resulten inútiles dentro de los órganos laborales del país.

De este mismo artículo, se desprenden postulados éticos valiosos, ya que el organismo sindical debe conocer como acceder a la justicia y más importante aún, como encaminar a sus agremiados a la solución de sus necesidades, problemas o conflictos que se presenten durante la prestación de sus servicios, por tal motivo, es determinante que el líder sindical, posea conocimiento legal, formación sindical y profesional adecuada a los requerimientos de su área de actuación, además de los procedimientos que puede utilizar para la protección de sus agremiados.

Existe también dentro del ordenamiento jurídico, la modelación y aplicación de las normas de orden laboral, es por ello, que el artículo 24 de la LOTTT (2012), establece necesario, e importante, que la administración de justicia se efectué tomando en consideración ciertos factores que contribuyan a la construcción de las relaciones laborales justas y equilibradas, por tanto, es ético, necesario y propio, que el líder sindical se actualice de forma permanente, para que también pueda dar cumplimiento y agregar valor al proceso social de trabajo y se eleve el nivel de vida de sus agremiados.

De conformidad con este principio, los sindicatos y sus integrantes participan directamente en el cumplimiento y prosecución de relaciones laborales cada vez más justas e igualitarias con el firme propósito de enaltecer el trabajo como fuente de riqueza, y como derecho humano indispensable para el progreso social y la lucha contra la pobreza. De conformidad con este principio, el trabajo, según Caldera (1957:55), es el "hecho social" que agrega valor $y$ que coadyuva al surgimiento de las civilizaciones; similares planteamientos refieren Rodríguez y Vílchez (2017). En tal sentido, es ético asegurar y propender al desarrollo humano con base al trabajo.

\section{5. Ética en Organizaciones Sindicales venezolanas}

Partiendo del hecho, que en la Constitución de la República Bolivariana de Venezuela (1999), se garantizan, no solo las libertades sindicales como se establece el su artículo 95, sino también la posibilidad de que estas aspiren modificar sus condiciones laborales a través del instrumento legal conocido como la "Convención Colectiva", fundamentada en el artículo 96 Constitucional, se analizarán y se establecerán las consideraciones éticas destinadas a enervar las situaciones de avance y de posible debilitamiento sindical existentes, con el propósito de fortalecer tales desventajas.

En este estado, encontramos que la LOTTT (2012), mantuvo las disposiciones relativas al proceso de trámite y negociación colectiva de forma preferente para las organizaciones sindicales, a este respecto, la propia ley emplea un lenguaje más sencillo a la hora de enumerar los derechos a que las partes intervinientes se contraen, sobre la base de tales preceptos se desprende el artículo 431 LOTTT (2012) y Noroño et al, (2020c).

A este mismo tenor, es una práctica honorable y ética, tomar en 
consideración las recomendaciones y sugerencias de los miembros del sindicato reunidos en asamblea para la redacción de su proyecto de convención colectiva de trabajo que se pretenda discutir con la entidad de trabajo, es importante verificar las necesidades propia de cada sector de la empresa o cada proceso productivo, con el fin o propósito de contemplar de forma integral todas las actividades en las que se encuentran los agremiados, por tal motivo, se recomienda realizar entrevistas y reuniones con cada departamento en donde se recojan las inquietudes y necesidades de cada una de ellas.

Luego de lo anterior, se redactará el proyecto de convención colectiva, para lo cual se recomienda utilizar como base de expresión de los cálculos, el salario mínimo o unidades tributarias, ya que definir el clausulado con base en bolívares, deprecia los montos en virtud de lo volátil de la economía de los últimos años y no se auto revisarían en el tiempo, por lo que resultaría más provechoso el uso de tales unidades. Las convenciones colectivas, además de la protección legal, es uno de los propósitos más deseados de la fundación y legalización de un organismo sindical, ya que cada dos (2) años como mínimo y cada tres (3) años como máximo, la ley indica que se deben revisar sus estipulaciones, según se establece en el artículo 435 LOTTT (2012).

De este modo, todos los afiliados se sentirán tomados en cuenta y que también participan en la elaboración, redacción y discusión del medio establecido en la ley para mejorar su calidad de vida, una vez introducido, se recomienda la participación de observadores de las diferentes áreas de trabajo y de los diferentes centros de trabajo o unidades de producción, con el propósito de brindar seguridad, tranquilidad y transparencia a la hora de empezar con el proceso de negociación colectiva, las cuales deben ser establecidas en la primera reunión a que se contraen según el artículo 439 LOTTT (2012). Siendo este un aspecto novedoso en la búsqueda de un nuevo modelo teórico-legal que persiga la ética como forma de dirigir los caminos sindicales en Venezuela.

Después de tomar estas consideraciones, los organismos sindicales, deben establecer cláusulas de aplicación retroactiva de ser posible, con la finalidad de perseguir los beneficios que en razón del tiempo invertido en el proceso de negociación pueda ser calculado y los trabajadores reciban el beneficio en la forma como sean pactados, ya sea, de forma individual o con la implementación de un monto único por cada trabajador amparado, a este respecto, se recomienda que tales consideraciones posean carácter salarial e impacten las prestación de antigüedad de cada beneficiario, de conformidad con el artículo 433 de la LOTTT (2012). Es ético perseguir la progresividad de los beneficios, lo que no es ético, es mantener los beneficios convencionales estáticos, aludiendo circunstancias ajenas al proceso de negociación.

Sin embargo, esto no quiere decir, que los trabajadores que entren con posterioridad a la firma de una convención colectiva estén en desventaja, con respecto a aquellos que estuvieron activos durante el proceso de negociación, ya que como se analizó en el artículo 432 LOTTT (2012), las estipulaciones aplican de inmediato para todos los trabajadores, incluso, para aquellos que no forman parte de la organización sindical, y que no apoyaron 
el proyecto de convención colectiva. Además de la obligatoriedad de incluir las mejoras en los contratos individuales de trabajo que se puedan celebrar en el futuro, en síntesis, todo se ajusta a la nueva norma pactada entre las partes.

De conformidad con lo que antecede, la ley Orgánica del Trabajo (1997) y La Ley del Trabajo $(1936)^{5}$, hicieron especial énfasis en el desarrollo del concepto del "hecho social", en razón a tales exposiciones, la LOTTT (2012), define en mayor grado la protección del Estado sobre los beneficios laborales en el marco de la discusión del proyecto de convención o contrato colectivo, a este respecto, se enuncia en el artículo 434 LOTTT (2012).

Es importante acotar, que existe una buena forma de poner en primer lugar los beneficios colectivos, esta técnica fue señalada por el Filósofo Mill (1863), el cual generó una serie de postulados que todo organismo sindical debe observar, en especial cuando se discute un proyecto de convención colectiva de Trabajo, tales preceptos, fueron denominados "Utilitarismo", que no es más, que la toma de decisiones basadas en el beneficio de las mayorías.

En este sentido, es esencial, realizar consultas a los agremiados sobre las decisiones, propuestas, formulas y posturas por asumir con respecto al clausulado que se aprobará en el ámbito de tales discusiones. Por lo tanto, se recomienda que las decisiones sobre el alcance, validez y efectividad del clausulado del proyecto de convención colectiva, sea ampliamente discutido en asamblea y las decisiones enfocadas en lo que a la mayoría le benefician.

Debido a las consideraciones anteriores, un sindicato no podrá disminuir, menoscabar, cambiar, estancar, paralizar, eliminar, ni retroceder los beneficios ya adquiridos mediante la lucha sindical, en el entendido, que para cambiar o permutar clausulas, se deberá dejar constancia de las implicaciones con fundados motivos que justifiquen el cambio, además, es falso que el líder sindical en solitario puede desmejorar un instrumento de tal magnitud, en principio necesita de la anuencia de los trabajadores que autorizan el depósito de la convención colectiva con la firma de un acta de asamblea y acto seguido, se necesita que el inspector del trabajo así lo permita y emita la homologación.

Una vez realizado el proceso de negociación, la ley establece que tal producto de la concertación debe ser revisado por las autoridades laborales, y son tales entes los responsables de dictar un auto de homologación donde se pone en marcha la ejecución y aplicación de la nueva norma entre las partes.

Durante décadas, las organizaciones sindicales han hecho vida en el país y en la sociedad, por ello, son ampliamente conocidas en todos los sectores de la economía, sin embargo, el reto histórico representa el cambio necesario de paradigma que se debe imprimir en estas oxidadas estructuras de organización social, como tal, hacen vida frecuente en las Inspectorías del

5 Ley del Trabajo de 16 de julio de 1936, elaborada y redactada por la Oficina Nacional del Trabajo, siendo para entonces su subdirector, quién después fuera presidente de Venezuela, el Dr. Rafael Caldera.

6 INPSASEL: Instituto Nacional de Prevención, Salud y Seguridad Laborales. https://www. medicinalaboraldevenezuela.com.ve/inpsasel.html 

Ética en las organizaciones sindicales venezolanas: una mirada desde lo teórico-legal_

Trabajo, modernamente en El Instituto Nacional de Prevención, Salud y Seguridad Laborales - INPSASEL 6 , $y$ poco menos en los tribunales y las defensorías del Pueblo.

Es frecuente, observar el tránsito de organismos sindicales en el trámite de reclamaciones de diferente índole, por cuanto, están dadas a resolver las necesidades y solicitudes de sus agremiados, sin embargo, el factor ético y el compromiso, forman la clave del éxito de la gestión sindical, por cuanto, perderían su misión y propósito si incumplieran con la ardua tarea que implica la representación y protección de la clase trabajadora.

En tal asignación, honrosa por demás, deben coexistir en una relación simbiótica con funcionarios contratados y pagados por el Estado venezolano para dar oportuna respuesta a sus solicitudes, procesos y reclamos, es allí, donde el componente ético y la formación sindical juegan un papel importante, por cuanto, en criterio de Noroño (2019:46) estos actores públicos pudieran no poseer hipotéticamente hablando, del mismo grado de compromiso de clase y por tal motivo afectar la gestión del líder sindical.

Es en este escenario, donde el líder sindical debe demostrar como lo indica Marx, "conciencia de clase", que no, es más, que el rol de responsabilidad asumido en el cuidado, defensa y protección de sus iguales ante los organismos públicos, partidos políticos, el entorno empresarial y el Estado, reflejándose en el compromiso de velar, por los beneficios de sus agremiados, o "su misma clase".

A pesar de esto y a sabiendas de los lapsos, tiempos y momentos que cada proceso legal lleva implícito, la efectividad sindical empezará a depender del grado de celeridad con que las instituciones públicas resuelvan las solicitudes planteadas, en este sentido, vale la pena acotar, que desde la creación del Registro Nacional de Organizaciones Sindicales, los lapsos que están tarifados en la ley ya no son respetados, y cuando antes se tardaban 3 meses en la recepción, revisión e inscripción de una organización sindical, al centralizar este organismo en la ciudad de Caracas, todo es más tardío y hoy día, la fundación de un sindicato hasta puede tardar fácilmente un (1) año, contrastando con Crouch (1983:333)

\section{Conclusiones}

Una vez abordado todo el desarrollo de la presente Investigación, se realizan las siguientes conclusiones; en primer lugar, se debe fortalecer la ética sindical, señalando las prácticas que son éticas y las que son opacas, a los fines de modelar la conducta del dirigente y se destaca en alto grado, que en la LOTTT (2012), se encuentran disposiciones que facilitan el trabajo del líder, del organismo sindical y de los agremiados, así mismo, se determinó mediante el estudio que las estrategias empresariales pueden perseguir el debilitamiento de la unión de los trabajadores, aludir a su falta de comunicación como herramienta divisoria, e intentar coludir al dirigente con el discurso empresarial y que este, pierda el norte de su real función, como lo es, defender al trabajador y perseguir sus mejoras socioeconómicas.

Se concluye que el dirigente tiene una gran responsabilidad en la tarea de lograr la progresividad y continuidad de los beneficios derivados de la convención colectiva, de la defensa integral de los acuerdos y cuerpo clausular derivado de dicho proceso de negociación, así como 
de enervar las reclamaciones, habida cuenta, de los incumplimientos que se detecten, por otra parte, el dirigente debe elevar su nivel de educación, formación y capacitación a los fines de poseer un alto grado de compromiso, valores y sobre todo de ética de clase, es decir, lealtad por quién lo respalda, apoya y en él cifra sus aspiraciones de mejora continua.

Seconcluye, queel comportamiento ético del dirigente impacta el alto grado al beneficio colectivo, al progreso de sus agremiados, aunque se demostró que la legislación aplicable "dirige" al líder, siempre estarán presente oportunidades donde este componente ético debe prevalecer, por cuanto, los procesos de negociación no están exentos de estrategias patronales que intenten incidir en el estancamiento o baja progresividad de los beneficios establecidos.

Por último, se concluye que, fundamentándose en la formación, la capacitación y la educación se puede transformar el comportamiento ético que deben desplegar las organizaciones sindicales a los fines de cumplir con sus propósitos socio-legales en beneficio de sus agremiados, evitando la baja conflictividad y una pobre actuación sindical, es necesario refrescar cada tres años, según Noroño (2014:107a), Carrieri y Donólo (1983:66) las juntas directivas de los sindicatos, para reimpulsar el espíritu defensivo en la organización y retomar la senda ética que tanto beneficia a los agremiados y a las relaciones laborales.

\section{Referencias bibliográficas}

Añez, C. (2007) Pequeñas Empresas en las Cadenas Productivas: Crecimiento o Dependencia. Revista
Análisis de Coyuntura, XIII(1). https:// www.redalyc.org/pdf/705/70504807. $\underline{\mathrm{pdf}}$

Añez, C. y Bonomie, M. (2007). Las relaciones laborales y sindicatos en el contexto adverso a la globalización. Revista venezolana de gerencia, 12(37), 50- 65.

Añez, C. (2014). Subordinación, flexibilización y relaciones laborales encubiertas. Revista Venezolana De Gerencia, 19(67). https://doi. org/10.37960/revista.v19i67.7441

Baquero, T., \& Liñan, A. (2020). Incidencia de la pandemia covid-19 en la economía del Estado colombiano. Utopía y Praxis Latinoamericana, 25(1), 292-302. http://doi. org/10.5281/zenodo.4087644

Bonomie, M. y Añez, C. (2014). Reflexión teórica de las estrategias flexibilizadoras en el marco de la globalización. Revista Venezolana de Gerencia (RVG), 14(48), 592-605 https://www.produccioncientificaluz. org/index.php/rvg/article/ view/10552/10540

Carrieri, M., y Donólo, C. (1983). Oltre l'orizzonte neo-corporatista. Alcuni scenari sul futuro politico del sindicato. Stato e Mercato, (9), 475503.

Cortina, A. (2013). ¿Para qué sirve realmente la ética? Editorial Paidós.

Crouch, C. (1983). The Politicsof Industrial Relations, Londres, Fontana, 1978. - "The State, Capital and Liberal Democracy», en CROUCH, C. (ed): State and Economy in Contemporary Capitalism, Londres, Croom Helm, 1979, pp. 13-54. - «State, Market and Organisation: A Classification of the Contribution of Neo-Corporatist Theory», mimeo, 1981. Versión italiana publicada como «Stato, Mercato e Organizzazione: la Teoría 
Noroño Sánchez, José Gregorio; Baquero Suarez, Tania Marina; Villchez Pirela, Rafael Ética en las organizaciones sindicales venezolanas: una mirada desde lo teórico-legal_

Neo-corporativa», Stato e Mercato, (2), 1981, pp. 333-358.

Díaz, R. (2009). Los sindicatos en Venezuela de la negociación a la confrontación. Revista sobre relaciones Industriales y laborales, (41), 91-104.

Dickens, P., y Goodwin, M. (1981). Consciousness, corporatism and the local state. Working Papers in Urhan and Regional Studies, (26), University of Sussex, 1981.

Flórez, L., López, J., \& Vílchez, R.A. (2020). Niveles de resiliencia y estrategias de afrontamiento: reto de las instituciones de educación superior. Revista Electrónica Interuniversitaria de Formación del Profesorado, 23(3), 35-47. https://bit. ly/2Qgt6j2

Gaceta Oficial de la República de Venezuela $N^{\circ} 5.152$, extraordinaria (1997). Ley Orgánica del Trabajo, reformada el 6 de mayo de 2011, publicada en Gaceta Oficial $N^{\circ} 6024$, extraordinaria.

Gaceta Oficial de la República Bolivariana de Venezuela (2012). Ley Orgánica del Trabajo, los Trabajadores y las Trabajadoras $\mathrm{N}^{\circ}$ 6076, Decreto Presidencial Nº 8.938 del 07 de mayo de 2012. https://oig. cepal.org/sites/default/files/2012 leyorgtrabajo ven.pdf

Gamboa, T., Arellano, M., y Nava, Y. (2003). Estrategias de Modernización Empresarial: Procesos, Productos y Fuerza de Trabajo. Revista Venezolana de Gerencia, 8(24), 592606. https://produccioncientificaluz. org/index.php/rvg/article/view/9703

Mill, J. (1863) Utilitarismo. Editorial London: Parker, Son y Bourn. (p. 44)

Noroño, J. (2014a). Retos y perspectivas de las organizaciones sindicales en el contexto de la globalización de las relaciones laborales en Venezuela. Revista Electrónica Lex Laboro, VI. http://ojs.urbe.edu/index.php/ lexlaboro/article/view/2583/2377

Noroño, J. (2014b). Las relaciones laborales venezolanas en el contexto de la globalización. Revista Legem, 2(1). http://www.uniatlantico.edu.co

Noroño, J., y Seijo, C. (2016). Ética Sindical y Relaciones Laborales: Un valor impulsor en empresas Privadas. Editorial Publicia. https://amzn. to/3v38lk2

Noroño, J., y Acevedo, A. (2019). Integración Regional Como Mecanismo De Desarrollo Sustentable Latinoamericano: Punto De Vista Ontológico. Revista Sapienza Organizacional ULA, 6(11). http://bdigital2.ula.ve:8080/xmlui/ handle/654321/3021

Noroño, J. (2019). Transnacionalidad sindical. Herramienta de integración, cambio y equidad global. TEUKEN BIDIKAY. Revista Latinoamericana de Investigación en Organizaciones, Ambiente y Sociedad, 10(15), 225238. https://doi.org/10.33571/teuken. v10n15a10

Noroño, J., Gonzalez, R., Muñoz, H., y Nuñez, M. (2019c). Retos y perspectivas de las organizaciones sindicales en el desarrollo empresarial. Desde una visión global de las relaciones laborales en Venezuela y Colombia. Ediciones Unisinú. Colombia. https://bit.ly/3v7x4sX

Noroño, J. (2019d). Empresa, Sindicatos y Economías Emergentes Latinoamericanas. Editorial Académica Española. https://bit. Iy/32CVMoN

Noroño, J. (2019e). Desafíos y retos 
éticos del Sindicalismo. Editorial Académica Española.

\section{https://bit.ly/3vceY90}

Noroño, J. (2019f). Regional Integration, Emerging Economies and Trade Unions: Integration and synergy between the company, the unions and its impact on the economies. LAP LAMBERT Academic Publishing (28 de agosto de 2019). https://amzn. to/2QObJFQ

Noroño, J., Chacín, R., y Nuñez, M. (2019g). Interpretación Judicial: un enfoque socio jurídico: Un aporte a la teoría de interpretación jurídica (Spanish Edition). Editorial Académica Española. España. https:// www.amazon.com/-/es/RonaldJes \%C3\%BAs-Chac\%C3\%ADnFuenmayor/dp/6200041016

Noroño, J., Nuñez, M., \& González, R. (2020a). Ética sindical como mecanismo impulsor de competitividad en las pequeñas y medianas empresas. Utopía y Praxis Latinoamericana, 25(1), 154-173. https://produccioncientificaluz.org/ index.php/utopia/article/view/32648

Noroño, J., y Núñez Villavicencio (2020b) Gerencia en las pymes y el impacto de la ética sindical en la competitividad. Business Intelligence Big Data y Contabilidad Tridimensional.

Noroño, J., Chacín, R. F., Rubio, M. E., Polo, B.Y., Rocha, M. Y., Rodríguez, R. A., Ortegón, T. M., Orozco, I. A., Lafont, M. A., González, V. M., Cerra, O. D., Cabrales, A. D., Vertel, R. G. (2020c). Derechos Humanos: prácticas, problemáticas $y$ resistencias. Un análisis de contextos. Proceso de negociación colectiva como forma de amplitud sociojurídica. Dimensión sindical ontológica.

Offe, C. (1983). Korporatismus ais System
Nichtstaatlicher Makrosteurung? Universitaet Bielefeíd, mimeo, octubre 1983.

Organización Internacional del Trabajo, OIT (1995). DERECHO SINDICAL DE LA OIT. Normas y procedimientos https://www.ilo.org/ wcmsp5/groups/public/---ed norm/--normes/documents/publication/ wcms 087999.pdf

Rangel, C., y Alvarado, C. (2012). Ética como enfoque de la responsabilidad social: direccionamiento estratégico en universidades públicas. Omnia, 18(2), 95-108. http:// revistas.unipamplona.edu.co/ojs viceinves/index.php/FACE/article/ view/1617/800

Rodríguez, M. T., \& Vilchez, R. A. (2017). Valor agregado como indicador de calidad en programas académicos universitarios utilizando resultados de pruebas censales. Academia y Virtualidad, 10(1). https://bit. ly/2QhwLNw

Schmitter, Ph. (1983). Democratic Theory and Neo-Corporatist Practice», EUI Working Paper, núm. 74, 1983. También, en Social Research, vol. 50, núm. 4, invierno 1983, páginas 885-928. — «Interest Intermediation and Regime Governability in Contemporary Western Europe and North America», en BERGER, $S$. (ed.): Organizing Interests in Western Europe, Cambridge, Cambridge University Press, 1980, pp. $287-$ 330. - «Needs, Interests, Concerns, Actions, Associations and Modes of Intermediation: Toward a Theory of Interest Politics in Contemporary Society», inédito MSS., IIMWissenschaftszentrum, Berlín, marzo 1981. - «Organizzazione degli interessi e rendimento politico»

Thompson, A., y Strickland III, A.J. (1999). Administración Estratégica. 
Noroño Sánchez, José Gregorio; Baquero Suarez, Tania Marina; Villchez Pirela, Rafael Ética en las organizaciones sindicales venezolanas: una mirada desde lo teórico-legal_

Conceptos y Casos. Undécima Edición. Mc. Graw Hill.

Toscano, F. (2018). Metodología de la Investigación. Guía práctica con las preguntas más frecuentes en la elaboración de una tesis de derecho. Universidad Externado de Colombia. Bogotá, Colombia.

Urquijo, J. (2004). El Movimiento obrero venezolano. UCAB-OIT-INAESIM.

Villarreal, E., y Visbal, G. (2013). Dilemas éticos. Salud Uninorte, 29(1), 113123 https://bit.ly/3sHaYxM

Villasmil, H. (2006). Estudios de derecho del trabajo. Editorial Texto C.A. 